\title{
Respiratory Muscle Strength in Patients With Chronic Obstructive Pulmonary Disease
}

\author{
Nam-Sik Kim, MD¹, Jeong-Hwan Seo, MD, PhD ${ }^{1}$, Myoung-Hwan Ko, MD, PhD ${ }^{1}$, \\ Sung-Hee Park, MD, $\mathrm{PhD}^{1}$, Seong-Woong Kang, $\mathrm{MD}$, $\mathrm{PhD}^{2,3}$, Yu Hui Won, $\mathrm{MD}, \mathrm{PhD}^{1}$ \\ ${ }^{1}$ Department of Physical Medicine and Rehabilitation, Research Institute of Clinical Medicine of Chonbuk National \\ University-Biomedical Research Institute of Chonbuk National University Hospital, Jeonju; \\ ${ }^{2}$ Department of Rehabilitation Medicine and Rehabilitation Institute of Neuromuscular Disease, Yonsei University \\ College of Medicine, Seoul; ${ }^{3}$ Pulmonary Rehabilitation Center, Gangnam Severance Hospital, Seoul, Korea
}

\begin{abstract}
Objective To compare the respiratory muscle strength between patients with stable and acutely exacerbated (AE) chronic obstructive pulmonary disease (COPD) at various stages.

Methods A retrospective medical record review was conducted on patients with COPD from March 2014 to May 2016. Patients were subdivided into COPD stages 1-4 according to the Global Initiative for Chronic Obstructive Lung Disease guidelines: mild, moderate, severe, and very severe. A rehabilitation physician reviewed their medical records and initial assessment, including spirometry, maximum inspiratory pressure (MIP), maximum expiratory pressure (MEP), COPD Assessment Test, and modified Medical Research Council scale. We then compared the initial parameters in patients with a stable condition and those at AE status.

Results The AE group ( $\mathrm{n}=94$ ) had significantly lower MIP (AE, 55.93 \pm 20.57 ; stable, 67.88 $\pm 24.96 ; \mathrm{p}=0.006)$ and MIP\% (AE, 82.82 \pm 27.92 ; stable, 96.64 $\pm 30.46 ; \mathrm{p}=0.015)$ than the stable patient group $(\mathrm{n}=36)$. MIP, but not MEP, was proportional to disease severity in patients with AE and stable COPD.

Conclusion The strength of the inspiratory muscles may better reflect severity of disease when compared to that of expiratory muscles.
\end{abstract}

Keywords Chronic obstructive pulmonary disease, Respiratory muscles, Rehabilitation, Muscle strength, Dyspnea

\section{INTRODUCTION}

Chronic obstructive pulmonary disease (COPD) is one of the most common chronic lung diseases, characterized by airway limitation or obstruction. It is a progressive and partially reversible respiratory disorder which shows a particular chronic inflammatory response caused by toxins or gas inhalation [1-3]. One of the most charac-

Received August 3, 2016; Accepted December 5, 2016

Corresponding author: Yu Hui Won

Department of Physical Medicine and Rehabilitation, Chonbuk National University Hospital, 20 Geonji-ro, Deokjin-gu, Jeonju 54907, Korea. Tel: +8263-250-2781, Fax: +82-63-254-4145, E-mail: wonyh@jbnu.ac.kr

ORCID: Nam-Sik Kim (http://orcid.org/0000-0003-0731-729X); Jeong-Hwan Seo (http://orcid.org/0000-0002-6915-6674); Myoung-Hwan Ko (http:// orcid.org/0000-0002-0566-3677); Sung-Hee Park (http://orcid.org/0000-0002-4743-2551); Seong-Woong Kang (http://orcid.org/0000-0002-72793893); Yu Hui Won (http://orcid.org/0000-0003-2007-9652).

(c) This is an open-access article distributed under the terms of the Creative Commons Attribution Non-Commercial License (http://creativecommons.org/ licenses/by-nc/4.0) which permits unrestricted noncommercial use, distribution, and reproduction in any medium, provided the original work is properly cited. Copyright $\odot 2017$ by Korean Academy of Rehabilitation Medicine 
teristic symptoms of COPD is dyspnea and many factors are known to be involved in its mechanism, including airflow limitation, gas trapping, gas exchange abnormalities, mucus hypersecretion, respiratory muscle dysfunction, and skeletal muscle dysfunction [4-6]. Among these, skeletal muscle dysfunction is characterized by reduced muscle mass, reduced strength and endurance, atrophy of type I and IIa muscle fibers, and decreased oxidative enzyme capacity $[7,8]$. In terms of skeletal muscle dysfunctions, the quadriceps muscle has been primarily studied. Patients with COPD demonstrated increased ventilatory stress even with the same amount of exercise due to the accumulation of carbon dioxide and increases in lactic acid $[9,10]$. Respiratory muscles are also skeletal muscles, and respiratory muscle dysfunction in patients with COPD may be caused by hyperinflation of the lung or diaphragm flattening and shortening. As a result of respiratory muscle dysfunction, reduced inspiratory muscle strength and endurance increased the risk of hypercapnic respiratory failure, limited exercise, and acute exacerbation (AE), despite diaphragm adaptation $[11,12]$. Pulmonary rehabilitation (PR) in patients with COPD mitigates symptoms, increases exercise capacities and enhances psychological stability, ultimately contributing to the prevention of complications caused by respiratory failure [13-16]. Most rehabilitation guidelines recommended aerobic and muscle strengthening exercises for the arms and legs as the basic PR program. Currently, inspiratory muscle training (IMT) as part of respiratory muscle rehabilitation is recommended only for patients with inspiratory muscle weakness $[1,3]$. However, some reports suggest that respiratory muscle trainings, such as IMT in patients with respiratory muscle weakness, might improve dyspnea and subsequently the patient's quality of life [17-19]. IMT has been suggested for patients with inspiratory muscle weakness at the start of PR [3], but an adequate guideline has not yet been established to assess the minimal inspiratory muscle weakness level that requires IMT. In addition, specific data regarding the severity of inspiratory muscles in patients with COPD is lacking. To the best of our knowledge, a prior study classified maximum inspiratory pressure (MIP) and maximum expiratory pressure (MEP) according to COPD stage (mild, moderate, and severe) to show declines in MIP and MEP, and according to COPD severity in comparison with those in the control group [20]. As of yet, MIP\% and
MEP\%, as well as comparisons of severity-specific respiratory muscle strength between patients with stable and AE COPD have not been reported.

The present study aims to determine whether respiratory muscle strength (including inspiratory and expiratory muscles) decreases according to COPD stage, and whether such differences in respiratory muscle strength vary between patients with a stable condition and those at $\mathrm{AE}$ status.

\section{MATERIALS AND METHODS}

\section{Subjects}

A retrospective medical record review was conducted on patients with COPD from March 2014 to May 2016. The inclusion criteria were patients diagnosed with COPD with a forced expiratory volume in 1 second (FEV1)/forced vital capacity (FVC) of less than $70 \%$ in spirometry evaluation. The patients were consulted as inpatients or registered as outpatients at the Pulmonary Rehabilitation Center of Chonbuk National University Hospital, between March 2014 and May 2016. The severity of COPD was classified based on FEV1 predictions as follows: stage I (FEV1 $\geq 80 \%)$, stage II $(50 \% \leq \mathrm{FEV} 1<80 \%)$, stage III $(30 \% \leq \mathrm{FEV} 1<50 \%)$, and stage IV $(\mathrm{FEV} 1<30 \%)$, according to the Global Initiative for Chronic Obstructive Lung Disease (GOLD) standard, as suggested by the National Heart, Lung, and Blood Institute and the World Health Organization [2]. The AE group of COPD patients included those who required hospitalization for treatment with corticosteroids or antibiotics due to an acute worsening of respiratory symptoms [21]. Outcome parameters were measured within 7 days of onset of acute respiratory symptoms. The stable COPD group included outpatients with COPD who did not show deterioration of COPD.

\section{Measurement of outcome parameters \\ MIP and MEP representing respiratory muscle strength} were measured by using a mouth pressure meter, the MicroRPM (Micro Medical Ltd., Rochester, England) at baseline. The patients were instructed to inspire or expire through the mouthpiece. The data was recorded when the pressure was maintained for at least 1 second at the peak level, and the highest pressure among three trials was selected as the final. We calculated predicted MEP 
(MEP pred) and predicted MIP (MIP pred) based on the patients' ages, heights and weights. Then, relative MEP and MIP were presented as MEP\% and MIP\% [22]. According to recommendations of the American Thoracic Society and the European Respiratory Society, we measured FVC, FEV1, and the ratio of FEV1 to FVC (FEV1/ FVC) [23]. Then, we calculated predicted values for FEV1 using the Morris formula and calculated the FEV1\% [24]. We also performed the COPD Assessment Test (CAT) to examine the effects of COPD on the patient's daily lives [25]. Furthermore, we used the modified Medical Research Council (mMRC) scale to rate the severity of dyspnea from 0-4 [26].

\section{Statistical analyses}

Statistical analyses were performed by the SPSS ver. 18.0 program (SPSS Inc., Chicago, IL, USA). The MannWhitney U-test was used to compare the stages, mMRC scores and CAT scores, and the Student t-test was used to compare the MIPs and MEPs between the two patient groups. In addition, one-way analysis of variance was used to compare COPD stage-specific MIP and MEP, and the Kruskal-Wallis test was used to compare CAT and mMRC scores. All statistical data was considered significant at $\mathrm{p}<0.05$.

\section{RESULTS}

\section{General characteristics of the subjects}

Among 130 patients with COPD, 94 were classified into the AE COPD patient group and 36 into the stable COPD patient group. A total of 102 patients were men and 28

Table 1. General characteristics of the patient with COPD

\begin{tabular}{lccc}
\hline & $\begin{array}{c}\text { COPD } \\
\text { (total) }\end{array}$ & $\begin{array}{c}\text { COPD } \\
\text { with AE }\end{array}$ & $\begin{array}{c}\text { Stable } \\
\text { COPD }\end{array}$ \\
\hline Number of patients & 130 & 94 & 36 \\
Sex & & & \\
$\quad$ Male & 102 & 75 & 27 \\
\hline Female & 28 & 19 & 9 \\
\hline Age $(\mathrm{yr})$ & 71.34 & 72.47 & 68.41 \\
\hline Height $(\mathrm{cm})$ & 161.30 & 160.80 & 162.90 \\
\hline Weight $(\mathrm{kg})$ & 54.77 & 54.82 & 54.63 \\
\hline BMI $\left(\mathrm{kg} / \mathrm{m}^{2}\right)$ & 20.95 & 21.08 & 20.52 \\
\hline COPD stage & & & \\
\hline 1 & $4(3.1)$ & $0(0)$ & $4(11.1)$ \\
\hline 2 & $51(39.2)$ & $36(38.4)$ & $15(41.7)$ \\
\hline 3 & $58(44.6)$ & $46(48.9)$ & $12(33.3)$ \\
\hline 4 & $17(13.1)$ & $12(12.7)$ & $5(13.9)$ \\
\hline
\end{tabular}

Values are presented as mean \pm standard deviation or number (\%).

COPD, chronic obstructive pulmonary disease; $\mathrm{AE}$, acute exacerbation; BMI, body mass index.

Table 2. Comparisons of respiratory parameters in patients with stable and acute exacerbation of COPD at baseline

\begin{tabular}{lccl}
\hline & COPD with AE $(\mathbf{n}=\mathbf{9 4})$ & Stable COPD $(\mathbf{n}=\mathbf{3 6})$ & p-value \\
\hline COPD stage & $2.74 \pm 0.67$ & $2.50 \pm 0.87$ & $0.122^{\mathrm{a})}$ \\
MIP (cmH $\left.{ }_{2} \mathrm{O}\right)$ & $55.93 \pm 20.57$ & $67.88 \pm 24.96$ & $0.006^{* \mathrm{~b})}$ \\
\hline MIP (\% pred) & $82.82 \pm 27.92$ & $96.64 \pm 30.46$ & $0.015^{* \mathrm{~b})}$ \\
\hline MEP (cmH $\left.{ }_{2} \mathrm{O}\right)$ & $89.53 \pm 28.10$ & $97.44 \pm 36.45$ & $0.190^{\mathrm{b})}$ \\
\hline MEP (\% pred) & $82.37 \pm 22.17$ & $87.40 \pm 32.97$ & $0.318^{\mathrm{b})}$ \\
\hline FEV1 (L) & $0.92 \pm 0.29$ & $1.20 \pm 0.55$ & $0.001^{* \mathrm{~b})}$ \\
\hline FEV1 (\% pred) & $43.64 \pm 12.81$ & $51.22 \pm 21.45$ & $0.015^{* \mathrm{~b})}$ \\
FEV1/FVC (\%) & $47.79 \pm 9.27$ & $51.44 \pm 11.70$ & $0.065^{\mathrm{b})}$ \\
mMRC & $2.47 \pm 0.87$ & $2.00 \pm 1.12$ & $0.011^{* \mathrm{a})}$ \\
\hline CAT & $16.63 \pm 6.75$ & $15.33 \pm 6.42$ & $0.320^{\mathrm{a})}$ \\
\hline
\end{tabular}

Values are presented as mean \pm standard deviation.

COPD, chronic obstructive pulmonary disease; AE, acute exacerbation; MIP, maximal inspiratory pressure; MEP, maximal expiratory pressure; FEV1, force expiratory volume in 1 second; FVC, force vital capacity; mMRC, modified British Medical Research Council; CAT, COPD Assessment Test.

${ }^{*} \mathrm{p}<0.05$.

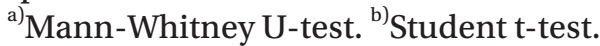


patients were women, with a mean age of 71.34 years. According to GOLD guideline, 4 patients were classified as mild, 51 as moderate, 58 as severe, and 17 patients as at a very severe stage (Table 1 ).

Respiratory functions of the AE and stable patient groups

No significant difference in COPD severity was found between the AE COPD patient group $(2.74 \pm 0.67)$ and stable COPD patient group (2.50 \pm 0.87$)$. However, the AE patient group had significantly lower MIP, MIP\%, FEV1, and FEV1\%, and significantly higher mMRC scale scores (Table 2).

The FEV1, FEV1\% and FEV1/FVC decreased while the mMRC and CAT score increased with increasing stage level in the AE patient group (Table 3). When we divided the patients into a mild-to-moderate group (stage 1 or 2) or a severe-to-very severe group (stage 3 or 4), the comparison showed similar results as presented in Table 3. MIP and MIP\% decreased significantly, and MMRC and

Table 3. Comparisons of parameters in AE COPD group according to different stages $(n=94)$

\begin{tabular}{lcccc}
\hline & Stage 2 $(\mathbf{n}=\mathbf{3 6})$ & Stage 3 $(\mathbf{n}=\mathbf{4 6})$ & Stage $4(\mathbf{n}=\mathbf{1 2})$ & p-value \\
\hline MIP $\left(\mathrm{cmH}_{2} \mathrm{O}\right)$ & $63.05 \pm 24.17$ & $51.34 \pm 17.20$ & $52.16 \pm 15.42$ & $0.028^{* a)}$ \\
MIP (\% pred) & $97.33 \pm 31.56$ & $74.80 \pm 21.70$ & $70.06 \pm 19.00$ & $<0.001^{* * * a)}$ \\
MEP $\left(\mathrm{cmH}_{2} \mathrm{O}\right)$ & $92.86 \pm 31.28$ & $85.13 \pm 27.55$ & $96.41 \pm 16.97$ & $0.311^{\mathrm{a})}$ \\
MEP (\% pred) & $85.85 \pm 23.64$ & $78.70 \pm 22.56$ & $86.01 \pm 13.63$ & $0.294^{\mathrm{a})}$ \\
FEV1 (L) & $1.08 \pm 0.29$ & $0.88 \pm 0.24$ & $0.56 \pm 0.11$ & $<0.001^{* * * a)}$ \\
FEV1 (\% pred) & $53.33 \pm 9.55$ & $41.32 \pm 8.66$ & $23.50 \pm 4.14$ & $<0.001^{* * * a)}$ \\
FEV1/FVC (\%) & $52.05 \pm 8.63$ & $47.06 \pm 8.54$ & $23.50 \pm 4.14$ & $<0.001^{* * * a)}$ \\
mMRC & $2.11 \pm 0.94$ & $2.56 \pm 0.71$ & $3.25 \pm 0.62$ & $<0.001^{* * * b)}$ \\
CAT & $14.86 \pm 6.41$ & $16.32 \pm 6.00$ & $23.16 \pm 7.06$ & $0.001^{* * b)}$ \\
\hline
\end{tabular}

Values are presented as mean \pm standard deviation.

$\mathrm{AE}$, acute exacerbation; $\mathrm{COPD}$, chronic obstructive pulmonary disease; MIP, maximal inspiratory pressure; MEP, maximal expiratory pressure; FEV1, force expiratory volume in 1 second; FVC, force vital capacity; mMRC, modified British Medical Research Council; CAT, COPD Assessment Test.

${ }^{*} \mathrm{p}<0.05,{ }^{* *} \mathrm{p}<0.01,{ }^{* * *} \mathrm{p}<0.001$.

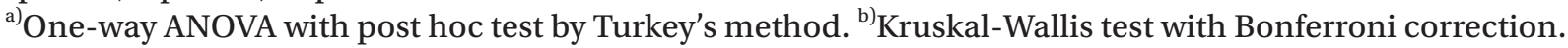

Table 4. Comparisons of parameters in AE COPD group dividing into either a mild to moderate or a severe to very severe group $(\mathrm{n}=94)$

\begin{tabular}{lccc}
\hline & Stage 2 $(\mathbf{n}=\mathbf{3 6})$ & Stage 3, $\mathbf{4}(\mathbf{n}=\mathbf{5 8})$ & p-value \\
\hline MIP $\left(\mathrm{cmH}_{2} \mathrm{O}\right)$ & $63.05 \pm 24.17$ & $51.51 \pm 16.72$ & $0.008^{* * a \mathrm{a})}$ \\
MIP (\% pred) & $97.33 \pm 31.56$ & $73.82 \pm 21.10$ & $<0.001^{* * * a)}$ \\
MEP ( $\left.\mathrm{cmH}_{2} \mathrm{O}\right)$ & $92.86 \pm 31.28$ & $87.46 \pm 26.00$ & $\left.0.368^{\mathrm{a}}\right)$ \\
MEP (\% pred) & $85.85 \pm 23.64$ & $80.21 \pm 21.13$ & $0.233^{\mathrm{a})}$ \\
FEV1 (L) & $1.08 \pm 0.29$ & $0.82 \pm 0.25$ & $<0.001^{* * a \mathrm{a})}$ \\
FEV1 (\% pred) & $53.33 \pm 9.55$ & $37.63 \pm 10.75$ & $<0.001^{* * * a)}$ \\
FEV1/FVC (\%) & $52.05 \pm 8.63$ & $45.15 \pm 8.72$ & $<0.001^{* * * a)}$ \\
mMRC & $2.11 \pm 0.94$ & $2.70 \pm 0.74$ & $0.002^{* * \mathrm{~b})}$ \\
CAT & $14.86 \pm 6.41$ & $17.74 \pm 6.77$ & $0.044^{* \mathrm{~b})}$ \\
\hline
\end{tabular}

Values are presented as mean \pm standard deviation.

$\mathrm{AE}$, acute exacerbation; COPD, chronic obstructive pulmonary disease; MIP, maximal inspiratory pressure; MEP, maximal expiratory pressure; FEV1, force expiratory volume in 1 second; FVC, force vital capacity; mMRC, modified British Medical Research Council; CAT, COPD Assessment Test.

${ }^{*} \mathrm{p}<0.05,{ }^{* *} \mathrm{p}<0.01,{ }^{* * *} \mathrm{p}<0.001$.

${ }^{\text {a) }}$ Student t-test. ${ }^{\text {b) }}$ Mann-Whitney U-test. 
CAT increased significantly with increasing stage level. However, MEP and MEP\% did not significantly vary in accordance with COPD severity (Table 4).

In the stable COPD group, MIP and MIP\% decreased in accordance with COPD stage. Both parameters showed a decreasing trend, but the differences between each stage were not statistically significant, except between stages 2 and 3 (Table 5). However, as the numbers of samples for stages 1 and 4 groups were too small, we divided the patients into either a mild-to-moderate (stage 1 or 2) or a severe-to-very severe group (stage 3 or 4 ) and found that MIP and MIP\% were significantly lower in the stage 3 or 4 group (Table 6). In contrast, MEP\% did not show a significant decline according to disease severity, as was the case in the previous analysis. MMRC and CAT scores were surprisingly lower in stage 4 than in stage 3 , indicating that symptom indexes are not positively correlated with disease severity in stable patients with COPD (Table 5). However, when patients were divided into either a mild-to-moderate group (stage 1 or 2), or a severe-to-very

Table 5. Comparisons of parameters in stable COPD group according to different stage ( $n=36)$

\begin{tabular}{|c|c|c|c|c|c|}
\hline & Stage $1(n=4)$ & Stage $2(n=15)$ & Stage $3(n=12)$ & Stage $4(n=5)$ & p-value ${ }^{a)}$ \\
\hline $\mathrm{MIP}\left(\mathrm{cmH}_{2} \mathrm{O}\right)$ & $84.50 \pm 10.66$ & $80.06 \pm 28.36$ & $54.41 \pm 11.22$ & $50.40 \pm 21.09$ & $0.005^{* *}$ \\
\hline MIP (\% pred) & $120.17 \pm 10.01$ & $115.65 \pm 27.94$ & $78.57 \pm 15.08$ & $64.13 \pm 21.81$ & $<0.001^{* * *}$ \\
\hline $\operatorname{MEP}\left(\mathrm{cmH}_{2} \mathrm{O}\right)$ & $116.25 \pm 30.10$ & $107.93 \pm 42.85$ & $81.00 \pm 26.70$ & $90.40 \pm 30.11$ & 0.133 \\
\hline MEP (\% pred) & $99.97 \pm 28.70$ & $89.87 \pm 40.35$ & $85.85 \pm 28.56$ & $73.67 \pm 22.97$ & 0.600 \\
\hline FEV1 (L) & $2.34 \pm 0.56$ & $1.30 \pm 0.30$ & $0.99 \pm 0.19$ & $0.52 \pm 0.10$ & $<0.001^{* * *}$ \\
\hline FEV1 (\% pred) & $92.25 \pm 10.71$ & $61.00 \pm 8.15$ & $39.75 \pm 5.36$ & $19.60 \pm 3.50$ & $<0.001^{* * *}$ \\
\hline FEV1/FVC (\%) & $63.00 \pm 7.78$ & $56.46 \pm 9.01$ & $48.16 \pm 9.71$ & $35.00 \pm 3.31$ & $<0.001^{* * *}$ \\
\hline mMRC & $1.25 \pm 0.50$ & $1.60 \pm 0.82$ & $3.00 \pm 1.22$ & $2.00 \pm 1.12$ & 0.050 \\
\hline CAT & $8.25 \pm 3.77$ & $14.93 \pm 6.70$ & $17.25 \pm 5.17$ & $15.33 \pm 6.42$ & 0.095 \\
\hline
\end{tabular}

Values are presented as mean \pm standard deviation.

COPD, chronic obstructive pulmonary disease; MIP, maximal inspiratory pressure; MEP, maximal expiratory pressure; FEV1, force expiratory volume in 1 second; FVC, force vital capacity; mMRC, modified British Medical Research Council; CAT, COPD Assessment Test.

${ }^{* *} \mathrm{p}<0.01,{ }^{* * *} \mathrm{p}<0.001$.

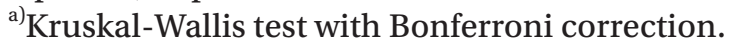

Table 6. Comparisons of parameters in stable COPD group dividing into either a mild to moderate or a severe to very severe group $(\mathrm{n}=36)$

\begin{tabular}{|c|c|c|c|}
\hline & Stage $1,2(n=19)$ & Stage $3,4(n=17)$ & p-value \\
\hline $\mathrm{MIP}\left(\mathrm{cmH}_{2} \mathrm{O}\right)$ & $81.00 \pm 25.46$ & $53.23 \pm 14.18$ & $<0.001^{* * *}$ a) \\
\hline MIP (\% pred) & $116.61 \pm 25.05$ & $74.33 \pm 17.93$ & $<0.001^{* * *}$ a) \\
\hline $\operatorname{MEP}\left(\mathrm{cmH}_{2} \mathrm{O}\right)$ & $109.68 \pm 39.93$ & $83.76 \pm 27.13$ & $0.031^{* \text { a) }}$ \\
\hline MEP (\% pred) & $91.99 \pm 37.70$ & $82.27 \pm 26.93$ & $0.385^{\text {a) }}$ \\
\hline FEV1 (L) & $1.52 \pm 0.56$ & $0.56 \pm 0.27$ & $<0.001^{* * *}$ a) \\
\hline FEV1 (\% pred) & $66.78 \pm 15.91$ & $33.82 \pm 10.60$ & $<0.001^{* * *}$ a) \\
\hline FEV1/FVC (\%) & $57.84 \pm 8.98$ & $44.29 \pm 10.28$ & $<0.001^{* * *}$ a) \\
\hline mMRC & $1.52 \pm 0.77$ & $2.52 \pm 1.23$ & $0.016^{* \mathrm{~b})}$ \\
\hline CAT & $13.52 \pm 6.71$ & $17.35 \pm 5.58$ & $0.074^{\mathrm{b})}$ \\
\hline
\end{tabular}

Values are presented as mean \pm standard deviation.

COPD, chronic obstructive pulmonary disease; MIP, maximal inspiratory pressure; MEP, maximal expiratory pressure; FEV1, force expiratory volume in 1 second; FVC, force vital capacity; mMRC, modified British Medical Research Council; CAT, COPD Assessment Test.

${ }^{*} \mathrm{p}<0.05,{ }^{* *} \mathrm{p}<0.01,{ }^{* * *} \mathrm{p}<0.001$.

${ }^{\text {a) }}$ Student t-test. ${ }^{\text {b) }}$ Mann-Whitney U-test. 
severe group (stage 3 or 4), the mMRC and CAT scores showed an increasing trend with increasing disease severity (Table 6).

\section{DISCUSSION}

Although various studies have investigated respiratory muscle strength assessment and PR for patients with COPD, none of them compared the MIP and MEP in accordance with disease severity between the $\mathrm{AE}$ and stable patient groups. The present study classified patients with COPD into AE and stable patient groups to compare their respiratory muscle strength and examine changes in respiratory muscle strength, in accordance with COPD stage level. The results showed that MIP was significantly lower in the AE group than the stable group even though they had similar severity of disease (Table 2). Furthermore, MIP was associated with COPD severity in both groups (Tables 4, 6). However, no significant reduction in MEP was observed in accordance with COPD severity.

Whereas MIP is known to be impaired by hyperinflation due to shortening of the inspiratory muscles, MEP is considered to be less influenced by respiratory mechanics. Reduction in MEP can be attributed to muscle weakness, which is common in advanced COPD [27]. Increasing airway resistance and end-expiratory lung volume during AE COPD status could exaggerate hyperinflation due to shortening of the inspiratory muscles. MIP is thus believed to be lower in patients with AE COPD, even in those with similar disease severity (Table 2).

MIP\% decreased in accordance with COPD stage in both the AE and stable COPD groups, a trend which was more clearly visible when the patients were divided into 'mild-to-moderate' and 'severe-to-very severe' COPD groups. The diaphragm is an inspiratory muscle that has an important function in MIP, and patients with COPD exhibit shortening and flattening of the diaphragm due to loss of elastic recoil in lung tissue $[28,29]$. Furthermore, patients with COPD have been reported to exhibit reduced inspiratory muscle function due to geometric changes of the thorax, including decreased external intercostal muscle strength $[20,30]$. Similarly, MIP was reduced in accordance with COPD severity in this study. Patients with stage 1 stable COPD showed a MIP\% of $120.17 \pm 10.01$, which was higher than the predicted value of MIP, and believed to be due to hyperinflation of the diaphragm in early inspiration as a result of resistive exercise.

In contrast, MEP\% tended to be lower in the 'severe-tovery severe' COPD group than in the 'mild-to-moderate' COPD group, but no clear reduction was correlated with increasing disease stage. Expiratory muscles, including the abdominal and internal intercostal muscles, increase expiratory flow by increasing intrathoracic pressure and decreasing lung volume. However, for patients with COPD, expiratory muscles are known to show heightened activity in order to increase expiratory flow when an expiratory resistance, such as a bronchospasm, is present $[31,32]$. Therefore, if expiratory resistance is present in patients with COPD, the expiratory muscles are further activated, which may result in MEP not decreasing with increasing COPD severity. Furthermore, Rochester and Braun [27] reported that MEP is less influenced by respiratory mechanics than MIP in patients with COPD. Another study also reported that MIP and expiratory muscle endurance must be assessed in order to examine the association between COPD and expiratory muscle endurance, due to such properties of expiratory muscles in patients with COPD [33].

The first limitation of this study is that the small number of patients with stable COPD hindered us from directly comparing them to patients with AE COPD. Future studies should examine a larger pool of patients with stable COPD to address this limitation.

Second, CAT scores showed an increasing trend in accordance with increasing severity in both $\mathrm{AE}$ and stable groups, but no difference in CAT scores was found between the two groups. However, a previous report showed that CAT scores of patients with AE COPD were approximately 5 points higher than those of patients with stable COPD [23]. One of the causes may be that the investigators who measured CAT scores were different for the patients with AE than those with stable COPD.

Third, this study calculated MEP\% and MIP\% by using the MIP and MEP prediction values that Wilson et al. [22] computed based on data from Caucasians. Thus, there may be a racial difference in predicted values of MIP\% and MEP\%. Future studies should examine Koreans to determine the normal predicted MIP and MEP values based on their ages, heights, and weights.

Although MIP reflects the disease severity of COPD better than MEP, no studies have been conducted to deter- 
mine a cutoff value for MIP that requires IMT. Therefore, future studies should identify a cutoff MIP value that requires IMT during a PR program.

In conclusion, the findings of this study suggest that MIP better reflects the disease severity of COPD than MEP, and MIP measured during the stable phase of COPD more accurately reflects inspiratory muscle strength than when measured during the AE phase. Furthermore, clinicians should reference the MIP of patients with COPD prior to the beginning of a PR program and use MIP as a parameter for treatment.

\section{CONFLICT OF INTEREST}

No potential conflict of interest relevant to this article was reported.

\section{ACKNOWLEDGMENTS}

This paper was supported by Fund of Biomedical Research Institute, Chonbuk National University Hospital.

\section{REFERENCES}

1. Marciniuk DD, Brooks D, Butcher S, Debigare R, Dechman G, Ford G, et al. Optimizing pulmonary rehabilitation in chronic obstructive pulmonary disease: practical issues: a Canadian Thoracic Society Clinical Practice Guideline. Can Respir J 2010;17:15968.

2. Rabe KF, Hurd S, Anzueto A, Barnes PJ, Buist SA, Calverley $\mathrm{P}$, et al. Global strategy for the diagnosis, management, and prevention of chronic obstructive pulmonary disease: GOLD executive summary. Am J Respir Crit Care Med 2007;176:532-55.

3. Spruit MA, Singh SJ, Garvey C, ZuWallack R, Nici L, Rochester C, et al. An official American Thoracic Society/European Respiratory Society statement: key concepts and advances in pulmonary rehabilitation. Am J Respir Crit Care Med 2013;188:e13-64.

4. Debigare R, Maltais F. The major limitation to exercise performance in COPD is lower limb muscle dysfunction. J Appl Physiol (1985) 2008;105:751-3.

5. Hyatt RE. Expiratory flow limitation. J Appl Physiol 1983;55:1-7.

6. O'Donnell DE, Revill SM, Webb KA. Dynamic hyper- inflation and exercise intolerance in chronic obstructive pulmonary disease. Am J Respir Crit Care Med 2001;164:770-7.

7. Gosselink R, Troosters T, Decramer M. Peripheral muscle weakness contributes to exercise limitation in COPD. Am J Respir Crit Care Med 1996;153:976-80.

8. Troosters T, Probst VS, Crul T, Pitta F, Gayan-Ramirez G, Decramer M, et al. Resistance training prevents deterioration in quadriceps muscle function during acute exacerbations of chronic obstructive pulmonary disease. Am J Respir Crit Care Med 2010;181:1072-7.

9. Casaburi R, Patessio A, Ioli F, Zanaboni S, Donner CF, Wasserman K. Reductions in exercise lactic acidosis and ventilation as a result of exercise training in patients with obstructive lung disease. Am Rev Respir Dis 1991;143:9-18.

10. Maltais F, Simard AA, Simard C, Jobin J, Desgagnes P, LeBlanc P. Oxidative capacity of the skeletal muscle and lactic acid kinetics during exercise in normal subjects and in patients with COPD. Am J Respir Crit Care Med 1996;153:288-93.

11. Gea J, Agusti A, Roca J. Pathophysiology of muscle dysfunction in COPD. J Appl Physiol (1985) 2013;114: 1222-34.

12. Levine S, Kaiser L, Leferovich J, Tikunov B. Cellular adaptations in the diaphragm in chronic obstructive pulmonary disease. N Engl J Med 1997;337:1799-806.

13. Seemungal TA, Donaldson GC, Bhowmik A, Jeffries DJ, Wedzicha JA. Time course and recovery of exacerbations in patients with chronic obstructive pulmonary disease. Am J Respir Crit Care Med 2000;161: 1608-13.

14. Pitta F, Troosters T, Probst VS, Spruit MA, Decramer M, Gosselink R. Physical activity and hospitalization for exacerbation of COPD. Chest 2006; 129:536-44.

15. Schmier JK, Halpern MT, Higashi MK, Bakst A. The quality of life impact of acute exacerbations of chronic bronchitis (AECB): a literature review. Qual Life Res 2005;14:329-47.

16. Puhan MA, Gimeno-Santos E, Scharplatz M, Troosters T, Walters EH, Steurer J. Pulmonary rehabilitation following exacerbations of chronic obstructive pulmonary disease. Cochrane Database Syst Rev 2011: CD005305.

17. Gosselink R, De Vos J, van den Heuvel SP, Segers J, Decramer M, Kwakkel G. Impact of inspiratory muscle 
training in patients with COPD: what is the evidence? Eur Respir J 2011;37:416-25.

18. Thomas MJ, Simpson J, Riley R, Grant E. The impact of home-based physiotherapy interventions on breathlessness during activities of daily living in severe COPD: a systematic review. Physiotherapy 2010;96: 108-19.

19. Geddes EL, O'Brien K, Reid WD, Brooks D, Crowe J. Inspiratory muscle training in adults with chronic obstructive pulmonary disease: an update of a systematic review. Respir Med 2008;102:1715-29.

20. Terzano C, Ceccarelli D, Conti V, Graziani E, Ricci A, Petroianni A. Maximal respiratory static pressures in patients with different stages of COPD severity. Respir Res 2008;9:8.

21. Burge S, Wedzicha JA. COPD exacerbations: definitions and classifications. Eur Respir J Suppl 2003;41: 46s-53s.

22. Wilson SH, Cooke NT, Edwards RH, Spiro SG. Predicted normal values for maximal respiratory pressures in Caucasian adults and children. Thorax 1984;39:535-8.

23. Miller MR, Hankinson J, Brusasco V, Burgos F, Casaburi R, Coates A, et al. Standardisation of spirometry. Eur Respir J 2005;26:319-38.

24. Morris JF, Koski A, Johnson LC. Spirometric standards for healthy nonsmoking adults. Am Rev Respir Dis 1971;103:57-67.

25. Jones PW, Harding G, Berry P, Wiklund I, Chen WH, Kline Leidy N. Development and first validation of the COPD Assessment Test. Eur Respir J 2009;34:648-54.

26. Bestall JC, Paul EA, Garrod R, Garnham R, Jones PW,
Wedzicha JA. Usefulness of the Medical Research Council (MRC) dyspnoea scale as a measure of disability in patients with chronic obstructive pulmonary disease. Thorax 1999;54:581-6.

27. Rochester DF, Braun NM. Determinants of maximal inspiratory pressure in chronic obstructive pulmonary disease. Am Rev Respir Dis 1985;132:42-7.

28. Butler C. Diaphragmatic changes in emphysema. Am Rev Respir Dis 1976;114:155-9.

29. Breslin EH, Garoutte BC, Kohlman-Carrieri V, Celli BR. Correlations between dyspnea, diaphragm and sternomastoid recruitment during inspiratory resistance breathing in normal subjects. Chest 1990;98: 298-302.

30. Mador MJ, Bozkanat E. Skeletal muscle dysfunction in chronic obstructive pulmonary disease. Respir Res 2001;2:216-24.

31. O'Donnell DE, Sanii R, Anthonisen NR, Younes M. Expiratory resistive loading in patients with severe chronic air-flow limitation: an evaluation of ventilatory mechanics and compensatory responses. Am Rev Respir Dis 1987;136:102-7.

32. Gorini M, Misuri G, Duranti R, Iandelli I, Mancini M, Scano G. Abdominal muscle recruitment and PEEPi during bronchoconstriction in chronic obstructive pulmonary disease. Thorax 1997;52:355-61.

33. Ramirez-Sarmiento A, Orozco-Levi M, Barreiro E, Mendez R, Ferrer A, Broquetas J, et al. Expiratory muscle endurance in chronic obstructive pulmonary disease. Thorax 2002;57:132-6. 